\title{
Annual decline of lung function in pulmonary emphysema: influence of radiological distribution
}

\author{
JA HUGHES, DCS HUTCHISON, D BELLAMY, DE DOWD, KC RYAN, \\ P HUGH-JONES \\ From the Chest Unit and Computer Unit, King's College Hospital and Medical School, London
}

\begin{abstract}
Fifty-six male patients with pulmonary emphysema and normal serum alpha -antitrypsin $^{2}$ were followed for a minimum period of three years (range 3-13 yr) to observe the effects of the radiological distribution of emphysema on the annual rate of change of lung function indices. The subjects were placed in three categories-upper zone (UZ), lower zone (LZ), and generalised (G). The influence of smoking was taken into account with subjects in each radiographic category being divided into ex-smokers (group EX-S) and continuing smokers (group S). The rate of decline of FEV VC, Tco, and Kco was greater in group $\mathrm{S}$ than EX-S in all three x-ray categories. In group $\mathrm{S}$, $\mathrm{FEV}_{1}, \mathrm{VC}$, Tco, and Kco declined significantly faster in UZ emphysema than in $\mathrm{G}$ emphysema. In group EX-S, $\mathrm{FEV}_{1}, \mathrm{TcO}$, and $\mathrm{PaO}_{2}$ declined significantly faster in UZ than $\mathrm{G}$ emphysema but VC remained unaltered. $\mathrm{KCO}$ and $\mathrm{PaCO}_{2}$ did not change significantly in any radiographic category in either group S or EX-S. Patients with G and LZ emphysema underwent very similar physiological changes over the course of time. Those with UZ emphysema, however, complained of exertional dyspnoea at an earlier age; a number of their lung function indices deteriorated at a faster rate than in patients from the other two categories, suggesting that UZ emphysema is a different disease entity.
\end{abstract}

In a parallel study from this unit ${ }^{1}$ of patients with established pulmonary emphysema, it was shown that the rate of decline in a number of lung function indices was significantly less in ex-smokers than in those who continued to smoke. It has been found possible to divide emphysematous patients on radiological criteria into an "upper zone" and a "lower zone" group ${ }^{2}$ with a third group in whom the lesions are more generally distributed; we have therefore carried out a further analysis, using data from patients incorporated in the above study, ${ }^{1}$ in order to assess the effects of the radiological type upon the changes in lung function.

\section{Patients and methods}

Fifty-six patients with emphysema (the same patients as studied by Hughes et $a^{1}$ ) were followed prospectively and fulfilled the following criteria. All were male subjects, who had attended for a minimum period of three years and had radiological evidence of pulmonary emphysema with vascular attenuation

Address for reprint requests: Dr DCS Hutchison, King's College Hospital Medical School, Denmark Hill London SE5 8RX. or destruction. ${ }^{3}$ The following groups were excluded from the study: patients with other types of severe lung disease or significant abnormalities on their chest radiograph (not attributable to emphysema); those who had undergone previous thoracic surgery; and patients with alpha ${ }_{1}$-antitrypsin deficiency who were homozygous for $\mathrm{Pi}$ type $\mathrm{Z}$ or heterozygous for type SZ.

The radiographs were seen by three of the authors-JAH, DCSH, and DB-and were divided into three radiological categories: UZ-"upper zone" emphysema, where the upper half of the lung fields was the more severely affected; LZ - "lower zone" emphysema, where the lower half of the lung fields was the more severely affected; G"generalised" emphysema, where there was no obvious difference between the two halves.

All patients were or had been cigarette smokers and were divided into two groups: smokers (S) and ex-smokers (EX-S). Group EX-S were defined as those who had stopped smoking before the time of entry into the study and who did not smoke thereafter. The mean time interval between cessation of smoking and entry was 4.2 years (range one month to 29 years). The remainder were all included in group $S$ 
and comprise those that smoked throughout the study, together with those smoking at the start who subsequently gave up.

The patients were seen by one of the authors on average once a year. At each visit a questionnaire was completed to establish the grade of dyspnoea and sputum production. ${ }^{4} \mathrm{~A}$ history of cigarette smoking at all periods of the patient's life was obtained and the total quantity of tobacco consumed was estimated in kilograms. ${ }^{5} \mathrm{Pi}$ type was assessed by starch gel electrophoresis. ${ }^{6}$

\section{LUNG FUNCTION}

Forced expiratory volume in one second $\left(\mathrm{FEV}_{1}\right)$ and slow vital capacity (VC) were performed at each visit, on a Bernstein spirometer, ${ }^{7}$ with the subject seated and a nose clip attached, before (pre bd) and 10 minutes after (post bd) two puffs $(200 \mu \mathrm{g})$ from a salbutamol metered dose aerosol; only the post bd results are reported. The best of five attempts for both VC and $\mathrm{FEV}_{1}$ were recorded. The transfer factor for carbon monoxide (TCO) was then measured by the single breath method. ${ }^{8} 9$ Permeability coefficient $(\mathrm{KCO})$ was calculated in the manner described by Cotes. ${ }^{10}$ Arterial samples were taken into heparinised syringes by puncture of either the radial or brachial artery and the arterial oxygen tension $\left(\mathrm{PaO}_{2}\right)$ and carbon dioxide tension $\left(\mathrm{PaCO}_{2}\right)$ were analysed immediately, up to the year 1976 on a Micro Electrode E5021a Radiometer and from 1976 on a Dow Corning Type 165 blood gas analyser.

\section{STATISTICAL METHODS}

The data were processed on the University of London Computer Centre's CDC 7600 using the GENSTAT statistical package. For each patient the linear regression coefficients of the selected variables on time were calculated. A weighted mean linear regression coefficient on time, together with its standard error was then calculated for each variable for groups $\mathbf{S}$ and EX-S. This enables any specified comparison of regression coefficients to be carried out using Student's $t$ test. For further details see the appendix to Hughes et al. ${ }^{1}$

\section{Results}

Fifty-six men with emphysema were studied, 17 with upper zone disease (UZ), nine with lower zone disease (LZ), and 30 with generalised (G) emphysema.

INITIAL ASSESSMENT: CLINICAL DATA

The number of subjects and their initial clinical data in both group $\mathbf{S}$ and group EX-S, in each radiographic category, are shown in table 1 .

\section{Comparison of groups $S$ and $E X-S$}

There was no difference ( $\mathrm{p}>0.05$ ) between group $S$ and group EX-S in any of the radiographic categories except in the LZ category where group EX-S had smoked significantly $(p<0.05)$ less tobacco than group $\mathrm{S}$. Dyspnoea grade and $\mathrm{Pi}$ type did not differ between the groups.

Group $E X-S$ No significant differences existed between the radiographic categories, at the initial assessment.

Group $S$ The findings were similar to group EX-S, except for age and the prevalence of bullae. The LZ patients were significantly older than those with $G$ emphysema ( $p<0.005)$ who in turn were older than those with UZ emphysema $(p<0.05)$. Bullae were more prevalent in UZ subjects than in those with $G$ emphysema ( $p=0.02$ Fisher's exact test).

\section{INITIAL ASSESSMENT:LUNG FUNCTION DATA \\ Comparison of groups $S$ and $E X-S$}

No significant differences between group $S$ and group EX-S, at the time of initial assessment, were observed in any of the categories except for $\mathrm{KcO}$ in the UZ subjects where group EX-S had significantly $(p<0.001)$ higher values than group $S$. The lung function indices at the time of initial

Table 1 Initial assessment: clinical data

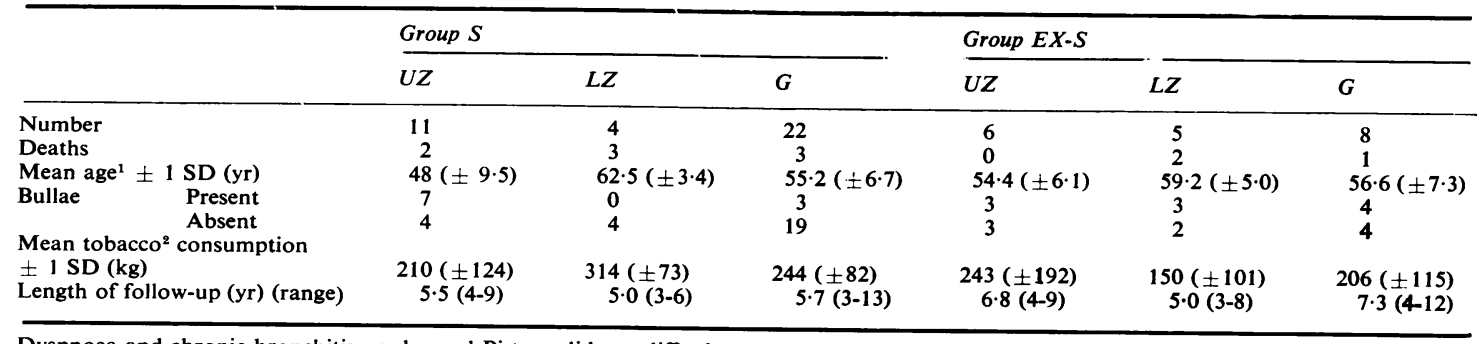

Dyspnoea and chronic bronchitis grades and Pi type did not differ between groups.

'Significance of differences in age between various groups: group $\mathrm{S}$ : UZ vs $\mathbf{L Z} \mathrm{p}<0.001 ; \mathrm{UZ}$ vs $\mathrm{G}$ p $<0.05 ; \mathrm{LZ}$ vs $\mathrm{G} \mathrm{p}<0.005$.

${ }^{2}$ Significance of difference in tobacco consumption between LZ group S and group EX-S p $<0.05$ 
Table 2 Initial lung function data (mean $\pm 1 S D)$

\begin{tabular}{|c|c|c|c|c|c|c|}
\hline & \multicolumn{3}{|l|}{ Group $S$} & \multicolumn{3}{|c|}{ Group $E X-S$} \\
\hline & $U Z$ & $L Z$ & $G$ & $U Z$ & $L Z$ & $G$ \\
\hline $\mathrm{FEV}_{1}$ (post bd) $\% \mathrm{p}^{1}$ & $64(-35)$ & $68( \pm 18)$ & $60(+43)$ & $65(+29)$ & $50( \pm 37)$ & $46(+21)$ \\
\hline $\mathrm{VC}$ (post bd) $\% \mathrm{p}$ & $106( \pm 28)$ & $108(-22)$ & $97( \pm 27)$ & $97( \pm 20)$ & $69(+31)$ & $90(+16)$ \\
\hline ТCO \% p & $61(+21)$ & $66( \pm 29)$ & $56( \pm 27)$ & $78( \pm 13)$ & $53( \pm 28)$ & $63(+32)$ \\
\hline $\mathrm{KCO}^{2} \% \mathrm{p}$ & $54(+18)$ & $63( \pm 26)$ & $56( \pm 20)$ & $88( \pm 12)$ & $64( \pm 35)$ & $72(\div 31)$ \\
\hline $\mathrm{PaO}_{2} \mathrm{mmHg}$ & $74(+10)$ & $77( \pm 8)$ & $69( \pm 9)$ & $73(+13)$ & $66( \pm 18)$ & $69(+9)$ \\
\hline $\mathrm{PaCO}_{2} \mathrm{mmHg}$ & $38( \pm 5)$ & $38( \pm 3)$ & $40( \pm 6)$ & $39(+5)$ & $45(+10)$ & $38(+8)$ \\
\hline
\end{tabular}

$1 \% \mathrm{p}$ : Expressed as percentage of predicted value.

"Significance of difference in KCO in UZ subjects between group S and group EX-S p $<0.001$.

Conversion factor: $\mathrm{kPa} \quad \mathrm{mmHg} \div 7.5$.

assessment in these groups are shown in table 2 There were no significant differences between any of the categories.

\section{ANNUAL RATES OF CHANGE IN LUNG FUNCTION VARIABLES}

The annual change in lung function variables in subjects with $L Z$ and $G$ emphysema behaved in a similar way in both groups with the following exceptions. $\mathrm{PaO}_{2}$ in groups $\mathrm{S}$ and $\mathrm{EX}-\mathrm{S}$ declined significantly ( $p<0.001$ ) faster in type $L Z$ than in type $G$; and for TCO, in group EX-S, where LZ subjects decline significantly $(p<0.05)$ faster than $G$.

The annual rate of decline in $\mathrm{FEV}_{1}$ was significantly different from zero in UZ subjects (both groups $\mathbf{S}$ and EX-S) and in group $\mathbf{S}$ subjects with type $G$ emphysema. The rate of decline was faster in group $S$ than in group EX-S for all three radiographic categories, and for both group $\mathbf{S}$ and group EX-S, the rate of decline was faster in UZ subjects than in $\mathrm{LZ}$ and $\mathrm{G}$ subjects (table 3 ).

Table 3 Regression coefficients for $F E V_{1}$ (post bd) in $\mathrm{ml}$ per annum $\pm 1 S E$ for different $x$-ray zones

\begin{tabular}{|c|c|c|c|c|c|}
\hline & Group $S$ & $p_{1}$ & Group $E X-S$ & $p_{1}$ & $p_{2}$ \\
\hline $\begin{array}{l}\text { UZ } \\
\text { LZ } \\
p_{3} \\
G \\
p_{4}\end{array}$ & $\begin{array}{l}-86.2( \pm 9.6) \\
-37.9( \pm 16.7) \\
<0.001 \\
-43.1( \pm 7.9) \\
<0.001\end{array}$ & $\begin{array}{l}<0.001 \\
\mathrm{NS} \\
<0.001\end{array}$ & $\begin{array}{l}-46.4( \pm 12.4) \\
-3.0( \pm 13.8) \\
<0.005 \\
-1.0( \pm 8.7) \\
<0.001\end{array}$ & $\begin{array}{l}<0.005 \\
\text { NS } \\
\text { NS }\end{array}$ & $\begin{array}{l}<0.001 \\
0.05 \\
<0.001\end{array}$ \\
\hline
\end{tabular}

Negative value represents a fall in the variable.

$p_{1}$ value vs zero (ie no change in lung function with time).

$\mathrm{p}_{2}$ group $\mathrm{S}$ vs group EX-S.

$p_{3}$ UZ vs LZ.

$p_{4}$ UZ vs G.

NS $p \cdot 0 \cdot 05$.

The annual rate of decline in VC was significantly different from zero $(p<0.001)$ only in UZ subjects of group $S$ (table 4 ). The rate of decline was faster in group $\mathbf{S}$ than in group EX-S for all three radiographic categories, but the difference was significant only in UZ subjects $(p<0.001)$. In group $S$, the rate of decline was faster in patients with UZ emphysema than in those with LZ or G
( $p<0.001$ ). In group EX-S, the rate of change was similar in all three categories.

Table 4 Regression coefficients for VC (post bd) in $m l$ per annum $\pm I S E$ for different $x$-ray zones

\begin{tabular}{|c|c|c|c|c|c|}
\hline & Group $S$ & $p_{1}$ & Group EX-S & $p_{1}$ & $p$ \\
\hline $\begin{array}{l}\text { UZ } \\
\text { LZ }\end{array}$ & $\begin{array}{l}-104 \cdot 2(+18 \cdot 6) \\
-30 \cdot 0(+20 \cdot 1)\end{array}$ & $\begin{array}{l}<0.001 \\
\text { NS }\end{array}$ & $\begin{array}{l}-1 \cdot 0( \pm 18.8) \\
-2.0( \pm 24.4)\end{array}$ & $\begin{array}{l}\text { NS } \\
\text { NS }\end{array}$ & $\begin{array}{l}<0.001 \\
\mathrm{NS}\end{array}$ \\
\hline $\begin{array}{l}p_{3} \\
G \\
p_{4}\end{array}$ & $\begin{array}{l}<0.001 \\
-26.4(+14.6) \\
<0.001\end{array}$ & NS & $\begin{array}{l}\text { NS } \\
+5 \cdot 2( \pm 18 \cdot 8) \\
\text { NS }\end{array}$ & NS & NS \\
\hline
\end{tabular}

Negative value represents a fall in the variable.

Positive value represents an increase in the variable. $\mathrm{p}_{1}$ value vs zero.

$\mathrm{p}_{2}$ group $\mathrm{S}$ vs group EX-S.

$\mathrm{p}_{3}$ UZ vs LZ.

$\mathrm{p}_{4}$ UZ vs G.

The rate of change in Tco differed significantly from zero only in UZ subjects of group $S(p<0.001)$. A small but non-significant increase occurred in group EX-S subjects with G emphysema (table 5). The rate of decline was faster in group $S$ than in group EX-S only in subjects with $G$ emphysema $(p<0.02)$. In UZ emphysema, both group $S$ and and EX-S declined significantly faster than their counterparts with $\mathrm{G}$ emphysema.

Table 5 Regression coefficients for $T_{C o}$ in $\mathrm{mmol}$ $k \mathrm{~Pa}^{-1} \mathrm{~min}^{-1}$ per annum $\pm I S E$ for different $x-r a y$ zones

\begin{tabular}{llllll}
\hline & Group $S$ & $p_{1}$ & Group EX-S & $p_{1}$ & $p_{2}$ \\
\hline UZ & $-0.19( \pm 0.04)$ & $<0.001$ & $-0.09( \pm 0.07)$ & NS & NS \\
LZ & $-0.14(+0.11)$ & NS & $-0.06(+0.07)$ & NS & NS \\
$\mathrm{p}_{3}$ & $\mathrm{NS}$ & $\mathrm{NS}$ & & \\
$\mathrm{G}$ & $-0.05( \pm 0.03)$ & $\mathrm{NS}$ & $+0.04( \pm 0.04)$ & $\mathrm{NS}$ & $<0.02$ \\
$\mathrm{p}_{4}$ & $<0.001$ & & $<0.05$ & & \\
$\mathrm{p}_{5}$ & $\mathrm{NS}$ & & $<0.05$ & &
\end{tabular}

Negative value represents a fall in the variable.

Positive value represents an increase in the variable.

$p_{1}$ value vs zero.

$\mathrm{p}_{2}$ group $\mathrm{S}$ vs group EX-S.

$\mathrm{p}_{3} \mathrm{UZ}$ vs LZ.

$p_{4} U Z$ vs $G$.

$p_{5}$ LZ vs G.

To convert to $\mathrm{ml} \mathrm{mm} \mathrm{Hg}^{-1} \min ^{-1}: \times 2.99$.

The rate of change in Kco did not differ significantly from zero in group $\mathrm{S}$ or EX-S in any radio- 
graphic category. There was a marginal increase of Kco in group EX-S subjects and in group $S$ with $G$ emphysema (table 6). Groups $S$ and EX-S did not differ in any radiographic category, but in group $\mathrm{S}$, the rate of decline was significantly faster in $\mathrm{UZ}$ emphysema than in $G$ emphysema.

Table 6 Regression coefficients for Kco in $\mathrm{mmol}$ min $^{-1} \mathrm{kPa}^{-1} L^{-1}$ per annum $\pm 1 S E$ in different $x$-ray zones

\begin{tabular}{llllll}
\hline & Group $S$ & $p_{1}$ & Group EX-S & $p_{1}$ & $p_{2}$ \\
\hline UZ & $-0.002( \pm 0.011)$ & NS & $+0.005( \pm 0.016)$ & NS & NS \\
LZ & $-0.004( \pm 0.026)$ & NS & $+0.027( \pm 0.024)$ & NS & NS \\
$\mathrm{p}_{3}$ & NS & & NS & & \\
G & $+0.018( \pm 0.01)$ & NS & $+0.018( \pm 0.011)$ & NS & NS \\
$\mathrm{p}_{4}$ & $<0.05$ & & NS & &
\end{tabular}

Negative value represents a fall in the variable.

Positive value represents an increase in the variable.

$p_{1}$ value vs zero.

$\mathrm{p}_{2}$ group $\mathrm{S}$ vs group EX-S.

$p_{3}$ UZ vs LZ.

$p_{4}$ UZ vs G.

To convert to $\mathrm{ml} \min ^{-1} \mathrm{~mm} \mathrm{Hg}^{-1} \mathrm{~L}^{-1}: \times 2.99$.

The rate of decline in $\mathrm{PaO}_{2}$ differed significantly from zero in both group $S$ and EX-S in all three categories (table 7). Groups $S$ and EX-S did not differ in any radiographic category. In group $S$, $\mathrm{PaO}_{2}$ declined significantly faster in $\mathrm{LZ}$ emphysema than in $\mathrm{UZ}$ emphysema $(\mathrm{p}<0.001)$. In group EX-S, $\mathrm{PaO}_{2}$ declined faster in $\mathrm{UZ}$ emphysema than in $G$ emphysema $(p<0.05)$.

Table 7 Regression coefficients for $\mathrm{PaO}_{2}$ in $\mathrm{mm} \mathrm{Hg}$ per annum $\pm 1 S E$ for different $x$-ray zones

\begin{tabular}{llllll}
\hline & Group $S$ & $p_{1}$ & Group EX-S & $p_{1}$ & $p_{2}$ \\
\hline UZ & $-1.1( \pm 0.5)$ & $<0.05$ & $-2.0( \pm 0.7)$ & $<0.02$ & NS \\
LZ & $-4.4( \pm 1.0)$ & $<0.01$ & $-3.3( \pm 0.8)$ & $<0.005$ & NS \\
$\mathrm{p}_{3}$ & $<0.001$ & & $\mathrm{NS}$ & & \\
$\mathrm{G}$ & $-1.4( \pm 0.4)$ & $<0.001$ & $-0.7( \pm 0.2)$ & $<0.01$ & $\mathrm{NS}$ \\
$\mathrm{p}_{4}$ & $\mathrm{NS}$ & & $<0.05$ & & \\
$\mathrm{p}_{5}$ & $<0.001$ & & $<0.001$ & & \\
\hline
\end{tabular}

Negative value represents a fall in the variable.

Positive value represents an increase in the variable.

$p_{1}$ value vs zero.

$p_{2}$ group $S$ vs group EX-S.

$p_{3}$ UZ vs LZ.

$p_{4}$ UZ vs G.

$p_{5}$ LZ vs G.

$\mathrm{PaCO}_{2}$ did not change significantly in any radiographic category in either group $\mathbf{S}$ or EX-S.

\section{RADIOLOGICAL CHANGES}

In the UZ smokers, only two of the seven with bullae developed clear measurable enlargement of a single large bulla. In one patient, the bulla increased from $11 \mathrm{~cm}$ in its maximum diameter to $20 \mathrm{~cm}$ over a period of five years. In a second patient, followed for 13 years, a $7 \mathrm{~cm}$ bulla appeared de novo. There was no obvious change in the remaining patients.
Two of the UZ ex-smokers had clearly demarcated bullae; in one the diameter of the bulla enlarged from 19 to $22 \mathrm{~cm}$ over six years and in the other from 13 to $14 \mathrm{~cm}$ over eight years.

In $\mathbf{L Z}$ and $\mathrm{G}$ emphysema there was little change in the radiographic appearances.

\section{Discussion}

In the present report we have confirmed our observation $^{1}$ that in patients with emphysema, for the majority of lung function indices, the rate of decline is faster in smokers than in ex-smokers. We have also found that the radiological distribution of emphysema has a considerable influence on the rate of change in lung function.

Emphysema of the upper zones of the lungs has previously been considered as a separate disease entity from emphysema of the lower zones, ${ }^{211}$ as judged on the radiographic appearance of vascular attenuation or bullae, which are good indicators of the presence of emphysema. ${ }^{3}$ The precise extent and type of emphysema cannot, however, be assessed on such criteria and the distinction that we have made between the $\mathrm{UZ}$ and $\mathrm{LZ}$ types of emphysema indicates only the predominant radiographic lesions and does not imply that emphysema is confined to one area. In our assessment, the UZ lesions were generally much more obviously demarcated and bullae were more plentiful; the small number who fell into the LZ group indicates that these lesions could seldom to our satisfaction be visually separated from the more generalised disease.

Each of these three radiological groups was then divided into smokers and ex-smokers as in the previous study. We have demonstrated ${ }^{1}$ that the various indices of lung function do not decline in parallel and it has been previously shown, in the case of $\mathrm{FEV}_{1}{ }^{12}$ and of maximal mid-expiratory flow $^{13}$ that the rate of change is not linear, the curve entering a plateau phase with the passage of time. It is therefore of importance to establish that the various groups of patient have equivalent starting values of lung function so that valid comparisons of the rates of change can be made.

The initial clinical data (table 1) are comparable for grades of dyspnoea and chronic bronchitis, $\mathbf{P i}$ type, length of follow-up, and mortality. The main differences relate to group $S$, where subjects with $\mathrm{UZ}$ emphysema are significantly younger and have a greater prevalence of bullae than those with $G$ and LZ emphysema. The overall tobacco consumption was higher in $L Z$ subjects than in either of the other two groups, but affects only a small number of patients. Although the mortality in the small $\mathrm{LZ}$ group was greater than in the UZ group, this was probably attributable to their greater age. 
The lung function data (table 2) are comparable, except for $\mathrm{KCO}$ which has reached a plateau in all six subgroups (see table 7). Slight, though insignificant differences occur in group EX-S, where mean $\mathrm{FEV}_{1}, \mathrm{TcO}$, and $\mathrm{Kco}$ are greater in subjects with UZ emphysema than in those with $G$ emphysema. Despite subjects in group $\mathrm{S}$ with $\mathrm{UZ}$ emphysema being significantly younger than subjects with $G$ and LZ emphysema, their initial lung function data are similar. As we shall see later, a faster decline brings their lung function to similar values. For $\mathrm{FEV}_{1}$ and $\mathrm{VC}$ we have reported only values obtained after administration of a bronchodilator aerosol, which as we have suggested elsewhere, ${ }^{1}$ yield more reliable results.

With regard to the annual decline in $\mathrm{FEV}_{1}$ and VC, the following points emerged: (1) Group S patients declined at a faster rate than EX-S patients for all radiological categories. (2) The UZ patients of group $S$ declined at a faster rate than group $S$ patients with the $L Z$ or $G$ types of emphysema. (3) In EX-S patients in categories LZ and G, these lung function indices underwent no significant change. In contrast there was a very significant fall in $F_{E V}$ in EX-S patients with the UZ type of emphysema, though VC surprisingly remained virtually unchanged as in the other radiological categories.

Cigarette smoking is thought to bring about the destruction of pulmonary elastic tissue either by excessive release of proteolytic enzymes ${ }^{1415}$ or by suppression of the protective effect of alpha 1 antitrypsin, ${ }^{16}$ or by a combination of the two. We might therefore expect the tissue destruction to be halted in ex-smokers, as indeed occurs in the $\mathbf{L Z}$ and $\mathrm{G}$ categories. We require some explanation, however, for the continuing decline in $\mathrm{FEV}_{1}$ among exsmokers of the UZ category. In the upright lung, mechanical stretching forces are much greater in the upper lobes; ${ }^{17}$ thus, stresses like coughing may well aggravate the damage already caused by proteolytic action. The greater prevalence of bullae in the UZ subjects supports this view though it was seldom that bullae were clearly demarcated. The progressive loss of elastic recoil thus leads to further collapse of the airways during forced expiration and further limitation of maximal expiratory flow. ${ }^{1819}$ It seems likely that in group $S$ patients the "mechanical" and "biochemical" factors combine to cause the destruction of lung tissue, whereas in group EX-S mechanical factors alone are responsible for the continuing decline in $\mathrm{FEV}_{1}$.

Why then does VC in these EX-S patients with UZ emphysema not decline in parallel with the $\mathrm{FEV}_{1}$ ? A possible explanation is that the collapsibility of the airways which limits performance of the $\mathrm{FEV}_{1}$, does not influence VC because the latter measurement is obtained during a "slow" manoeuvre. In the ex-smoker, the alveolar destruction responsible for decline in VC presumably comes to a halt, as suggested above.

Kco did not change significantly in any group. Tco falls significantly only in UZ group $S$ and parallels the fall of $\mathrm{VC}$ in this group, since TCO is approximately proportional to the product of $\mathrm{KCO}$ and VC. The small rise in Kco may reflect an increase in blood flow and hence pulmonary capillary volume in relatively unaffected alveoli. The significant fall of $\mathrm{PaO}_{2}$ with unchanging $\mathrm{PaCO}_{2}$ suggests that an increase in the degree of ventilation-perfusion mismatch is taking place, though for some reason this proceeds faster in the $\mathbf{L Z}$ than in other groups.

In this study, we observed that G and LZ emphysema had many similarities in physiological terms, suggesting that they may represent the same basic pathological process. The UZ patients, on the other hand, showed clear physiological differences from the other two types as well as having a greater prevalence of bullae. It has already been suggested 20 that the upper and lower zone radiological forms correspond to the two main pathological forms, centrilobular and panlobular emphysema. Centrilobular emphysema occurs most commonly in the upper lobes, whereas the panlobular form may be found throughout the lung, with a preference for the lower lobes when the disease is more advanced. ${ }^{1121}{ }^{22}$ Mitchell et $a l^{23}$ suggested that these two pathological types were not separate disorders, though Anderson and Foraker ${ }^{11}$ found definite clinical differences. Other more recent studies suggest that radiological evidence of upper zone emphysema is associated with the centrilobular type whereas lower zone changes are more likely to be panlobular. ${ }^{24}$ Our findings indicate that such radiological differences are also reflected by different functional courses.

Dr Hughes, Dr Bellamy, and Dr Dowd were supported by the Wellcome Trust. The authors are grateful to Mrs Claire Robertson for secretarial assistance, to the technical staff of the Chest Unit who carried out the lung function tests, and to Dr PJL Cook for assessing the alpha ${ }_{1}$ antitrypsin phenotypes.

\section{References}

1 Hughes JA, Hutchison DCS, Bellamy D, Dowd D, Ryan K, Hugh-Jones $P$. The influence of cigarette smoking and its withdrawal on the annual change of lung function in pulmonary emphysema. $Q J \mathrm{Med} 1982$; in press.

${ }^{2}$ Martelli NA, Hutchison DCS, Barter CE. Radiological distribution of pulmonary emphysema. Thorax 1974; 29:81-9. 
${ }^{3}$ Laws JW, Heard BE. Emphysema and the chest film: a retrospective radiological and pathological study. Br J Radiol 1962;35:750-61.

+ Medical Research Council. Definition and classification of chronic bronchitis. Lancet 1965;1:775-9.

${ }^{5}$ Hutchison DCS, Cook PJL, Barter CE, Harris H, HughJones P. Pulmonary emphysema and alpha ${ }_{1}$ antitrypsin deficiency. Br Med J 1971;1:689-94.

${ }^{6}$ Cook PJL. The genetics of alpha ${ }_{1}$ antitrypsin: a family study in England and Scotland. Ann Hum Genet 1974/5; 38:275-87.

' Bernstein L, D'Silva JL, Mendel D. The effect of the rate of breathing on the maximum breathing capacity determined with a new spirometer. Thorax 1952;7: 255-62.

${ }^{8}$ Olgilvie CM, Forster RE, Blakemore WS, Morton JW. A standardised breath holding technique for the clinical measurement of the diffusing capacity of the lung for carbon monoxide. $J$ Clin Invest 1957;36:1-17.

${ }^{9}$ Jones RS, Meade F. A theoretical and experimental analysis of anomalies in the estimation of pulmonary diffusing capacity by the single-breath method. $Q J$ Exp Physiol 1961;46:131-43.

${ }^{10}$ Cotes JE. Lung function. Third edition. Oxford: Blackwell Scientific Publications, 1975.

${ }^{11}$ Anderson AE, Foraker AG. Centrilobular emphysema and panlobular emphysema: two different diseases. Thorax 1973;28:547-50.

12 Howard $P$. The changing face of chronic bronchitis with airways obstruction. Br Med J 1974;2:89-93.

${ }^{13}$ Emirgil C, Sobol BJ, Varble A, Waldie J, Weinheimer B. Long-term course of chronic obstructive pulmonary disease. Am J Med 1971;51:504-12.

${ }^{14}$ Hutchison DCS. Alpha ${ }_{1}$ antitrypsin deficiency and pulmon- ary emphysema: the role of proteolytic enzymes and their inhibitors. Br J Dis Chest 1973;67:171-96.

15 Janoff A, Sloan B, Weinbaum G et al. Experimental emphysema induced with purified human neutrophil elastase: tissue localization of the instilled protease. Am Rev Respir Dis 1977;115:461-77.

16 Janoff A, Carp H. Possible mechanisms of emphysema in smokers. Am Rev Respir Dis 1977;116:65-72.

17 West JB. Distribution of mechanical stress in the lung, a possible factor in localisation of pulmonary disease. Lancet $1971 ; 1: 839-41$.

18 Jordanoglou J, Pride NB. Factors determining maximum inspiratory flow and maximum expiratory flow of the lung. Thorax 1968;23:33-7.

19 Leaver DG, Tattersfield AE, Pride NB. Contributions of loss of lung recoil and of enhanced airways collapsibility to the airflow obstruction of chronic bronchitis and emphysema. $J$ Clin Invest 1973;52:2117-8.

20 Hugh-Jones $\mathrm{P}$, Whimster W. The etiology and management of disabling emphysema. Am Rev Respir Dis 1978; 117:343-78.

${ }^{21}$ Heard BE. Pathology of chronic bronchitis and emphysema. London: Churchill, 1969:61-73.

22 Thurlbeck WM. The incidence of pulmonary emphysema: with observations on the relative incidence and spatial distribution of various types of emphysema. Am Rev Respir Dis 1963;87:206-15.

${ }^{23}$ Mitchell RS, Silvers GW, Goodman N, Dart G, Maisel JC. Are centrilobular emphysema and panlobular emphysema two different diseases? Hum Pathol 1970;1:433-41.

${ }^{24}$ Thurlbeck WM, Simon G. Radiographic appearance of the chest in emphysema. Am J Roentgenol 1978;130: 429-40. 